\title{
Morphological disparity in Plio-Pleistocene large carnivore guilds from Italian peninsula
}

\author{
Carlo Meloro \\ Acta Palaeontologica Polonica 56 (1), 2011: 33-44 doi: http://dx.doi.org/10.4202/app.2010.0037
}

Communities of large mammals exhibit changes in morphological diversity through space and time; changes that are possibly correlated to distinct aspects of the physical environment. Here, I explore shape changes in the trophic apparatus of large carnivore guilds, comparing extant communities with Quaternary ones, from peninsular Italy. Mandibular shape is quantified through geometric morphometrics and its disparity is computed for each carnivore guild. Patterns of morphospace occupation through space and time reveal that extant carnivore guilds are negatively influenced by number of artiodactyls. Very productive ecosystems show low values of morphological disparity because species tend to occupy central regions of the morphospace rather than extreme areas. Disparity of mandibular corpus shape remains relatively stable throughout the Quaternary in the large carnivore communities of the Italian peninsula. They exhibit similar values to extant guilds because the trophic apparatus did not evolved important morphological novelties. Interestingly, carnivore guilds of the late Pliocene (3.5 Ma) and early Pleistocene $(0.8 \mathrm{Ma})$ show over-dispersed or random morphospace occupation because of a depleted fauna, precluding successive structural changes. The same applies for the extant European carnivore guild as a result of recent extinctions without replacement.

Key words: Carnivora, geometric morphometrics, mandible shape, Quaternary, Italian Peninsula, Italy.

Carlo Meloro [carlo.meloro@hyms.ac.uk], Hull York Medical School, The University of Hull, Loxley Building, Cottingham Road Hull HU6 7RX, UK.

This is an open-access article distributed under the terms of the Creative Commons Attribution License (for details please see creativecommons.org), which permits unrestricted use, distribution, and reproduction in any medium, provided the original author and source are credited. 
Fof Full text $(265.7 \mathrm{kB})$ 